\title{
Use of explosibility diagrams in potentially explosive atmospheres
}

\author{
Adrian Matei ${ }^{*}$, Răzvan Drăgoescu, Nicolae Ianc, Emeric Chiuzan, and Florin Rădoi \\ National Institute for Research and Development in Mine Safety and Protection to Explosion - \\ INSEMEX, 32-34 G-ral Vasile Milea street, 332047, Petrosani, Hunedoara county, Romania
}

\begin{abstract}
Although the first research in the field was carried out by Davy in 1816, the first discovery emerged in 1891 when Le Chatellier defined the law for determining the explosive limits. Lower Explosive Limit (LEL) represents the lowest concentration of gas or vapours in air which is able to generate the explosion in the presence of an efficient ignition source. It is considered to be the same as the Lower Flammability Limit (LFL). Upper Explosive Limit (UEL) represents the highest concentration of gas or vapours in air which is able to generate the explosion in the presence of an efficient ignition source. It is considered to be similar with the Upper Flammability Limit (UFL) [1]. For the optimal management of underground or surface industrial environments, confined, obstructed or open environments, is required to know the point which defines the monitored atmosphere in relation with the explosion triangle. For confined underground environments, monitoring the atmosphere and using the explosibility diagrams are required during the closure process and also for re-opening the area. For underground environments specific to active mine workings and for industrial environments located on the surface, monitoring the atmosphere and using explosibility diagrams are required permanently.
\end{abstract}

\section{Use of explosive diagrams}

For the optimal management of the underground or surface industrial environments, semiclosed or open closed environments, it is necessary to know the position of the point that defines the monitored atmosphere in relation to the explosive triangle [2-4].

For the underground environments specific to the active mining works as well as for the industrial surfaces from the surface, the monitoring of the atmosphere as well as the use of explosive diagrams are permanently required [5-8]. For example, a gas composition specific to the closed industrial environments for which explosive diagrams are used is given and analysed.

\section{Coward - Jones explosion chart}

- For a closed area we have the following composition:

\footnotetext{
*Corresponding author: adrian.matei@insemex.ro
} 
- $\quad \mathrm{X}: \mathrm{CH}_{4}=6 \%$ vol.; $\mathrm{CO}=1 \%$ vol.; $\mathrm{O}_{2}=16 \%$ vol.; $\mathrm{H}_{2}=0.5 \%$ vol.; $\mathrm{CO}_{2}=2 \%$ vol.; $\mathrm{N}_{2}$ $=79 \%$ vol.

- Fuel gases with figures from 1 to 3 are noted, and their percentage concentration with $\mathrm{P}_{1}-\mathrm{CH}_{4} ; \mathrm{P}_{2}-\mathrm{CO} ; \mathrm{P}_{3}-\mathrm{H}_{2}$. The total concentration of $\mathrm{P}_{t}$ fuel gases will be given by the expression:

$$
\begin{gathered}
P t=P 1+P 2+P 3 \% \\
P_{t}=6+1+0,5=7,5 \%
\end{gathered}
$$

The explosive limits of the mixture are calculated with the ratio:

$$
\frac{P_{t}}{L_{t}}=\frac{P_{1}}{L_{1}}+\frac{P_{2}}{L_{2}}+\frac{P_{3}}{L_{3}}
$$

in which:

$\mathrm{Lt}$ - explosive limit

$\mathrm{L}_{1 \ldots 3}$ - Properties of gases ar shown in the Table 1.

Table 1. Properties of gases

\begin{tabular}{|c|c|c|c|c|}
\hline \multirow{2}{*}{ The name of the gas } & \multicolumn{2}{|c|}{ Explosive limits } & \multicolumn{2}{c|}{ Minimum combustion limits } \\
\cline { 2 - 5 } & lower & higher & Gas & Oxygen \\
\hline Methane & 5.0 & 15.0 & 5.9 & 12.2 \\
\hline Carbon monoxide & 12.0 & 74.0 & 13.8 & 6.1 \\
\hline Hydrogen & 4.0 & 74.0 & 4.3 & 5.1 \\
\hline
\end{tabular}

The minimum burning limit of the $\mathrm{L}_{\min }$ mixture is determined by the relation:

Where $L_{\min 1 \ldots 3}$ the minimum combustion limits corresponding to each combustible gas in the mixture.

The excess $\mathrm{N}_{\mathrm{ex}}$ nitrogen required is given by the relation:

$$
N_{e x}=\frac{L_{\text {min }}}{P_{t}}\left(N_{1}^{+} P_{1}+N_{2}^{+} P_{2}+N_{3}^{+} P_{3}\right)
$$

wherein: $\mathrm{N}+1,2,3$ - represent the $\mathrm{m}^{3}$ of $\mathrm{N}+$ that must be added for each $\mathrm{m}^{3}$ of combustible gas in order for the blending of the mixture to cease, these values are shown in Table 2.

Table 2. Parameters for combustion ceasing.

\begin{tabular}{|c|c|}
\hline Fuel gas & $\mathbf{m}^{\mathbf{3}}$ of $\mathbf{N}^{+}$necessary for the combustion to cease \\
\hline Methane & 6.07 \\
\hline Carbon monoxide & 4.13 \\
\hline Hydrogen & 16.59 \\
\hline
\end{tabular}

The concentration of $\mathrm{O}_{2}$ required at the minimum burning limit of the mixture is:

Thus:

$$
O_{2}=0.2093\left(100-N_{e x}-L_{\min }\right) \%
$$

The lower explosive limit of the mixture is: 


$$
\begin{gathered}
\frac{7.5}{L_{i}}=\frac{6}{5}+\frac{1}{12}+\frac{0.5}{4} \\
L_{i}=5.30 \%
\end{gathered}
$$

The upper explosive limit of the mixture is:

$$
\begin{gathered}
\frac{7.5}{L_{i}}=\frac{6}{15}+\frac{1}{74}+\frac{0.5}{74} \\
L_{i}=17.8 \%
\end{gathered}
$$

The excess $\mathrm{N}+$ required is:

$$
N_{\text {ex }}=\frac{6.22}{7.5}(6.07 \cdot 6+4.12 \cdot 1+16.59 \cdot 0.5)=40.51 \%
$$

The concentration of $\mathrm{O}_{2}$ required at the minimum burning limit of the mixture is:

$$
O_{2}=0.2093(100-40.51-6.22)=11.15 \%
$$

As a result, the point that defines the monitored atmosphere $\mathrm{X}$ (Fuels, oxygen) in our case $\mathrm{X}(7,5,16)$, is located inside the explosive triangle according to Figure 1.

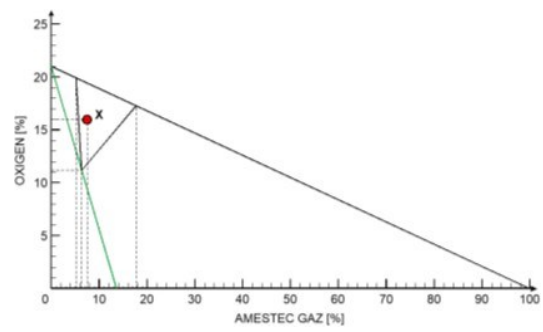

Fig. 1. Coward - Jones explosion chart.

\section{Ellicott explosion chart}

To use the Ellicott diagram, there have to be calculated the $\mathrm{X}$ and $\mathrm{Y}$ coordinates in relation to the nose point coordinates. The peak point is defined by the point 0 ( $\left.\mathrm{L}_{\min }, \mathrm{O}_{2 \mathrm{~min}}\right)$, in our case $0(6,22 ; 11,15)$.

Thus, we have:

$\mathrm{X}=7.5-6.22=+1,28 \%$ vol. $\mathrm{Y}=16-11.15=+4.85 \%$ vol.

Consequently, the point that defines the monitored atmosphere $\mathrm{X}$ (Fuels, oxygen) in our case $\mathrm{X}(+1.28 ;+4.85)$, is located inside the explosive zone according to Figure 2. 


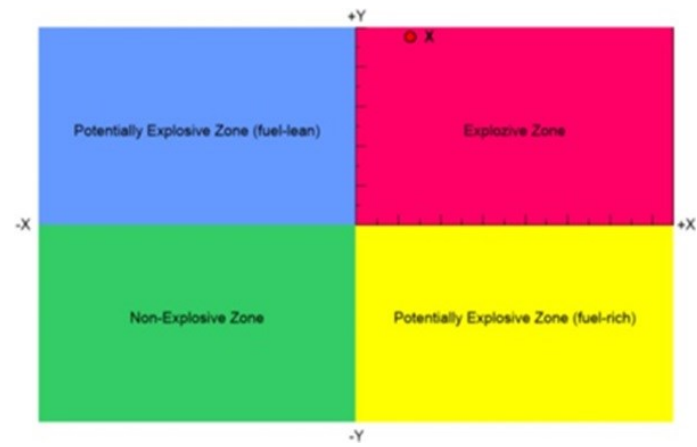

Fig. 2. Ellicott explosion chart.

\section{USBM explosion chart - Zabetakis}

For constructing explosive triangles, the ratio $\mathrm{R}$ between methane and total fuels is used:

Thus, we have:

$$
\begin{gathered}
R=\frac{\mathrm{CH}_{4}}{\mathrm{CH}_{4}+\mathrm{H}_{2}+\mathrm{CO}} \\
R=\frac{6}{6+1+0.5}=0.8
\end{gathered}
$$

The value corresponding to the inert gas concentration is determined. Inert cash $=\%$ excess $\mathrm{N}_{2}+1.5\left(\% \mathrm{CO}_{2}\right) \%$ vol.

Inert cash $=40.51+1.5(2)=43.51 \%$ vol.

The value corresponding to the concentration of the actual fuel gas is determined. Fuel efficiency $=\% \mathrm{CH}_{4}+1.25 \% \mathrm{H}_{2}+0.4 \% \mathrm{CO} \%$ vol.

Fuel efficiency $=6+1.25 \cdot 0.5+0.4 \cdot 1=7.025 \%$ vol.

As a result, the point defining the monitored atmosphere $\mathrm{X}$ (Effective inert, Effective fuels) in our case X $(43.51 ; 7.03)$, is located outside the explosive areas A1 and A2 explosive according to the value of parameter $\mathrm{R}$, in the area of non-explosive mixtures. but which can become explosive by the addition of air, Figure 3.

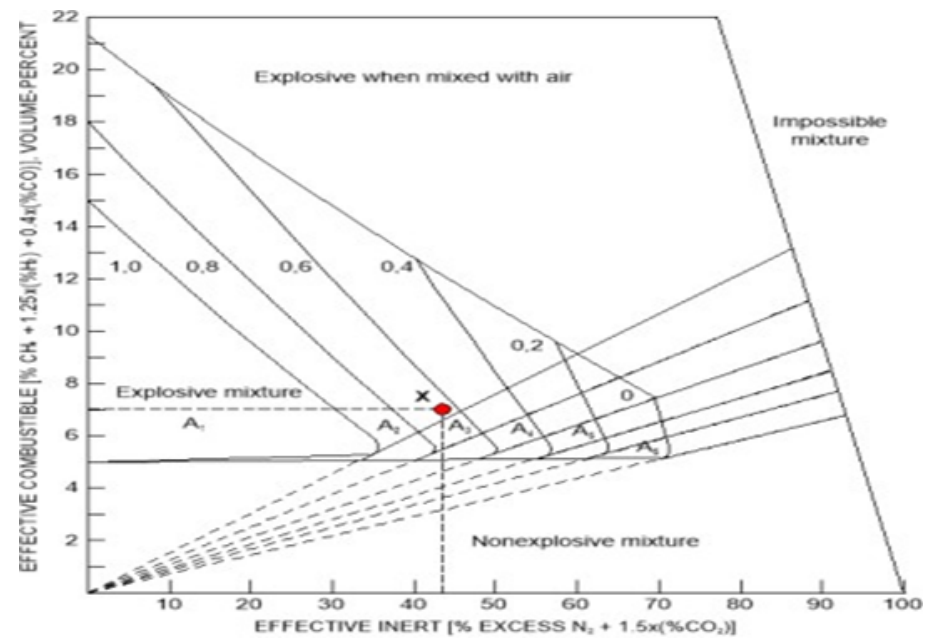

Fig. 3. USBM explosion chart - Zabetakis. 


\section{Ternare - Kennedy explosion chart}

For the use of the Ternare or Kennedy explosive diagram, we must only consider the concentrations of methane, oxygen and nitrogen.

Thus, the point $\mathrm{X}\left(\mathrm{CH}_{4}, \mathrm{O}_{2}, \mathrm{~N}_{2}\right)$ that defines the monitored atmosphere must be identified, in the case of our X $(6 ; 16 ; 79)$.

Consequently, the point that defines the monitored atmosphere $X\left(\mathrm{CH}_{4}, \mathrm{O}_{2}, \mathrm{~N}_{2}\right)$ in our case $\mathrm{X}(6 ; 16 ; 79)$, is located inside the flammability zone according to Figure 4 .

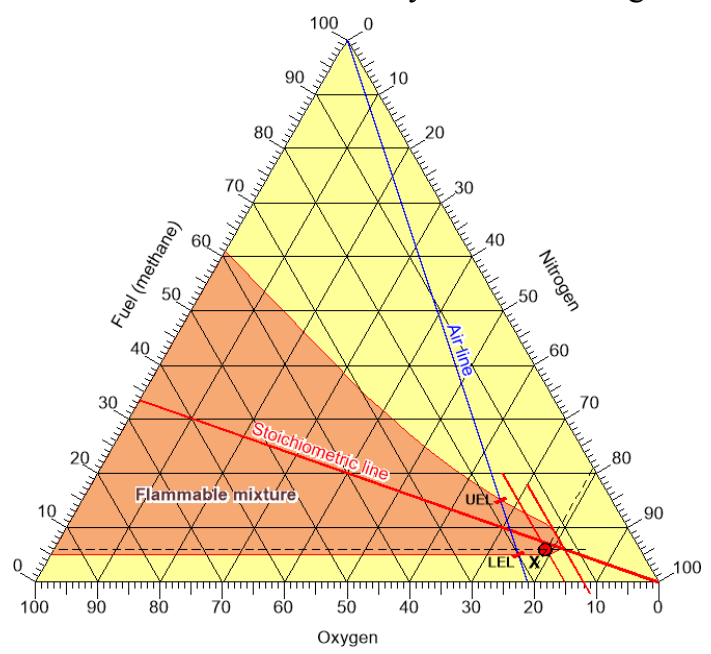

Fig. 4. Ternare - Kennedy explosion chart.

\section{CCSM - Bardocz explosion diagram}

In order to construct the flammability diagram of an explosive gas mixture, the following steps are taken [9]:

The points corresponding to the lower explosive limit of the explosive mixture $(5,3 \%$ vol.) and the upper explosive limit of the explosive mixture $(17,8 \%$ vol.) are marked on the parallel abscissa;

From these points is drawn the parallel with the ordinate until it intersects the diagonal of the diagram, which represents the oxygen line, in points A and B;

From point $\mathrm{A}$ is drawn a straight line parallel to the abscissa to point $\mathrm{C}$, which corresponds to the minimum required value of oxygen at which ignition is no longer possible (11,15\% vol.);

The points $\mathrm{A}, \mathrm{B}$ and $\mathrm{C}$ from which the flammable triangle of the explosive mixture results;

The oxygen concentration in the explosive gas mixture (16\% vol.) is identified on the oxygen scale, from which a parallel is drawn to the ordinate to the point corresponding to the maximum concentration of flammable gases $(7,5 \%$ vol.). This point is scored by 1 , a point that characterizes the position of the mixture in relation to the flammability triangle. As a result, the point that defines the monitored atmosphere 1 (Oxygen, fuels) in our case 1 $(16.0 ; 7.5)$, is located inside the explosive triangle, as presented in the Figure. 


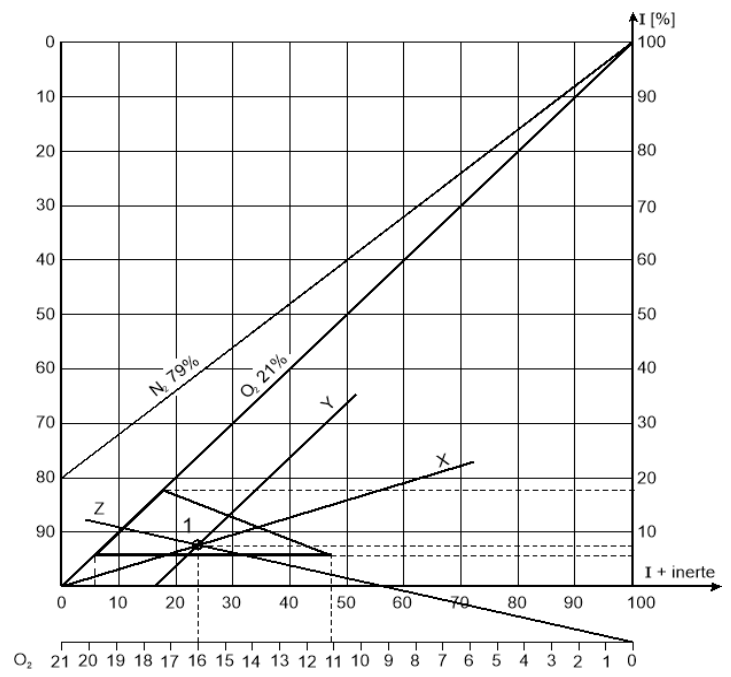

Fig. 5. CCSM - Bardocz Chart.

\section{Conclusions}

Human activity in general but industrial activity in particular, generates specific risks of underground fire, fire or explosion, which can result in human losses and significant material losses. All the listed risks can occur if three factors are overlapping in time and space, namely: fuel, oxygen and source of initiation.

Although the first research in the field was conducted by Davy in 1816, however, the first discovery came in 1891 when Le Chatelier discovered the law for determining explosive limits.

The lower and upper explosive limits define the explosive interval that is located inside a straight segment between the point characterized by $0 \%$ combustible gas and $100 \%$ air and the point $100 \%$ combustible gas and $0 \%$ air.

In 1952, H. F. Coward and G. W. Jones first presented the shape of the explosive triangle. Coward - Jones' explosive triangle was a $2 \mathrm{D}$ representation of the explosive atmosphere consisting of simple methane and air.

C. W. Ellicott modified the Coward-Jones diagram in 1981, in order to simplify it for easier practical use.

For this, Ellicott transformed the Coward - Jones explosive triangle into a $\mathrm{CH}_{4}-0-\mathrm{O}_{2}$ system, in a diagram in $\mathrm{X}$ and $\mathrm{Y}$, where $\mathrm{X}$ represents the relative concentration of combustible gases and $\mathrm{Y}$ represents the relative concentration of oxygen.

In 1959, M. G. Zabetakis, R. W. Stahl, and H. A. Watson, presented for the first time the USBM explosivity diagram or the Zabetakis diagram, for a mixture of methane, nitrogen, and air at $80^{\circ} \mathrm{F}$ and at atmospheric pressure.

K. Kennedy established in 1965 the method of making the triangular or ternary diagram. In the case of the construction of the Ternary or Triangular Kennedy diagram, for a mixture of combustible gas (methane) - oxygen - inert (nitrogen), it is positioned clockwise and rising on the sides of the triangle gas concentrations.

In 1977, V. Bardocz establishes the construction of the flammability triangle of a mixture of explosive gases consisting of oxygen, nitrogen, carbon dioxide, methane, carbon monoxide and hydrogen. Explosion diagram CCSM - Bardocz uses a binary system to represent flammable gas mixtures. 


\section{References}

1. H.F. Coward, G.W. Jones, Limits of flammability of gases and vapors, (U.S. Bureau of Mines, Bulletin 503, Washington, USA, 1952).

2. C. Teodorescu, Z. Gontean, I. Neag, Mining ventilation, (in Romanian), (Technical publishing house, Bucharest, 1980).

3. D. Carson, Classification en zones explosives poussiéreuses, (INERIS Report, Paris, 2001). Available on http://www.ineris.fr/centredoc/b.pdf

4. J. Cheng, Y. Luo, Journal of Loss Prevention in the Process Industries, 26, 714-722,

(2013). 5. J. Cheng, Y. Luo, Arch Min Sci, 59, (1), 25-40, (2014).

6. D.R. Echeverri, S. H. R. Cano, J. A. J. Builes, Revista Educacion en Ingenieria, 14, (7), (2012).

7. R. I. Moraru, Research and results in industrial and occupational safety, (in Romanian), (Habilitation thesis, University of Petrosani, 2015).

8. V. Bardocz, G. Neac, I. Focşa, Underground lignite gasification, (in Romanian), (CCSM Petrosani research study, Petrosani, 1977).

9. XXXX- Guidelines on Explosive atmospheres - Protection to explosion, http://www.materialeelectrice.ro/normalizari/Zone\%20antiex\%20co.pdf (in Romanian). 